\title{
O uso de simuladores via smartphone no ensino de física: $\mathrm{O}$ experimento de Oersted
}

The use of simulators by smartphone in physics teaching: the experiment of Oersted

\author{
C. D. Barbosa*; L. M. Gomes; M. L. das Chagas; F. C. L. Ferreira \\ Programa de Pós-Graduação em Ensino de Física, Universidade Federal do Sul e Sudeste do Pará, 68500-000, \\ Marabá - PA, Brasil. \\ *cairodb@gmail.com
}

(Recebido em 05 de setembro de 2016; aceito em 25 de novembro de 2016)

\begin{abstract}
Neste trabalho abordam-se aspectos teóricos de metodologias direcionadas para aplicação de simulações via smartphones voltadas para temas do Eletromagnetismo no Ensino Médio. Para atingir esse objetivo, são apresentadas propostas de como trabalhar através de smartphones o simulador "Oersted" desenvolvido pelo Sistema Brasileiro de Ensino S. A. (SBE) disponibilizado gratuitamente no Windows phone. Através do aplicativo é possível ao aluno interagir com a simulação de um dos experimentos mais importantes da Física, que promoveu a união entre a Eletricidade e o Magnetismo. Acredita-se que o uso de simulações através de smartphones no ensino, orientadas de forma pedagógica pode tornar estes aparelhos uma espécie de laboratório virtual portátil nas aulas de Física e ampliar as possibilidades de produzir ganhos na aprendizagem dos estudantes.
\end{abstract}

Palavras - chaves: Simuladores, smartphone, ensino de Física, experimento de Oersted.

In this work, it approaches theoretical aspects of methodologies directed to application simulations via smartphones aimed to Electromagnetism themes in high school. To achieve this goal, proposals are made on how to work through smartphones the simulator "Oersted" developed by the Brazilian Education System S.A. (SBE) available free in the Windows phone..Through the app is possible to the student interact with the simulation from one of the most important experiments of physics, which promoted the union between Electricity and Magnetism. It is believed that the use of simulations through smartphones oriented teaching educational way can make these devices, a sort of portable virtual lab in Physical and expand the possibilities to produce gains in student learning.

Keywords: Simulators, smartphones, teaching Physics, experiment of Oersted.

\section{INTRODUÇÃO}

Analisando as principais tecnologias que surgiram no decorrer da história e que provocaram modificações na forma de comunicação entre os seres humanos, é possível observar que estas também motivaram mudanças na forma de educar. Nos dias atuais, verifica-se uma infinidade de novas Tecnologias de Informação e Comunicação (TIC), onde, dentre estas merece destaque o Smartphone, aparelho portátil com um enorme potencial pedagógico, pois o mesmo permite tirar fotos, gravar vídeos, acessar a internet e baixar jogos e aplicativos diversos como calculadoras, dicionário, tradutores da língua, simuladores, etc.

Hoje, as tecnologias do conhecimento estão cada vez mais convergentes, as pessoas principalmente os jovens utilizam rotineiramente, celulares que possuem os mais diversos tipos de aplicativos e funções, dentre estas a internet, que proporciona informações de maneira rápida. O conhecimento passou a ficar condensado num aparelho portátil, onde para ter acesso basta um 
toque na tela ou o aperto de botão [1]. Diante de tamanhas inovações tecnológicas, observam-se assim grandes oportunidades pedagógicas.

A Física, assim como as demais disciplinas, deve adequar-se as transformações que surgem e a forma de como as informações são compartilhadas. A atenção do discente precisa ser estimulada através de aulas lúdicas, que lhe proporcionem algo de novo despertando o interesse e a motivação para aprender. Para este fim, é necessário investir na procura de novas metodologias que auxiliem a prática pedagógica do educando, pois o conhecimento a ser trabalhado deve ser significativo.

É expressivo o número de reprovações em Física nos diversos níveis de ensino, o que reflete bem a dificuldade que os alunos encontram nesta disciplina, sendo que esse quadro é observado em vários países [2].

Uma das peculiaridades da Física que a torna difícil, se deve ao fato do aluno lidar com conceitos abstratos e contra intuitivos, o que o leva a ter dificuldade em relacionar a Física com suas experiências do dia a dia. Além disso, existem os métodos de ensino ultrapassados, que não levam em consideração as mais recentes teorias de aprendizagem, assim como a falta da utilização de recursos pedagógicos mais modernos como, por exemplo, as novas tecnologias de informação e comunicação [2].

Pires e Veit (2006) [3] expõem que as aulas experimentais são cada vez mais raras, pois poucas escolas têm condições de manter em funcionamento um laboratório para o ensino de Física. Pensando nestes dois problemas, ou seja, nos conteúdos abstratos e nas dificuldades da realização de aulas práticas, uma alternativa que se apresenta viável para amenizar em grande parte tais problemas é a simulação virtual com o uso do smartphone.

Assim, é possível ensinar Física aos alunos de forma menos abstrata, já que a simulação apresenta uma modelagem do fenômeno real e também apresenta a vantagem de permitir ao discente aprender de forma bastante interativa.

Objetiva-se assim levar ao uso pedagógico do smartphone durante as aulas, de forma a trazer contribuição para o ensino de Física, mediante aulas lúdicas onde o aluno tenha um papel ativo no processo de ensino e aprendizagem, enquanto o professor tem a função de facilitador, orientador e provocador de reflexões.

Dessa forma para abordar o conteúdo será utilizado um aplicativo gratuito produzido pelo Sistema Educacional Brasileiro (SEB), que simula o experimento realizado pelo físico dinamarquês Oersted, descobridor da relação entre eletricidade e magnetismo.

Para o cumprimento ao proposto, utilizou-se de pesquisa teórica, buscando uma abordagem sobre o processo de ensino e aprendizagem e a quebra de alguns paradigmas, para então passar ao estudo do uso de simuladores gratuitos acessados via smartphone e formas de utilização de tais ferramentas como alternativas de metodologias de ensino para assuntos de Física no Ensino Médio.

\section{CONTEXTUALIZAÇÃo}

\section{1. SIMULADORES COMO UMA FERRAMENTA PEDAGÓGICA}

Observa-se atualmente que devido principalmente às novas tecnologias é surpreendente o volume de informações que surgem e a rapidez com que são transmitidas. Portanto, em vez de cobrar que conteúdos sejam decorados a ação do professor precisa enfocar o aprender e, principalmente, o "aprender a aprender" [4].

O que se pretende assim é proporcionar uma educação que se perpetue por toda a vida, onde o indivíduo saiba buscar novos conhecimentos, que se desenvolva neste o prazer em conhecer, aprender a pensar, a aplicar o conhecimento adquirido à realidade que está vivendo.

No entanto mesmo diante de tamanhas mudanças na transmissão da informação, verifica-se que o modelo educacional ainda vigente se enquadra naquilo que Freire (2005) [5] denominou de "educação bancária" baseada no estudo e memorização de conceitos e fórmulas de maneira mecânica e sem significado, onde verifica-se que muitos professores têm dado mais importância 
à memorização do que à compreensão e significação de assuntos estudados, o que geralmente leva o aluno a esquecer com facilidade o que "aprendeu".

Sendo assim, para uma aprendizagem mais significativa conforme Rogers (Rogers apud Moreira, 2011) [6], o aluno tem que verificar relevância nos conteúdos apresentados para atingir certo objetivo, precisa ainda ter uma participação ativa e responsável no processo de ensino e aprendizagem, ou seja, o educando deve escolher suas próprias direções, descobrir os seus próprios recursos de aprendizagem, formular problemas e encontrar soluções, com isso os assuntos são compreendidos e assimilados de forma mais fácil e rápida.

No ambiente educacional Lévy (1993) [7] tem o posicionamento de que a multimídia interativa é um instrumento bem ajustado a uma pedagogia ativa, pois favorece uma atitude exploratória, até mesmo lúdica, diante do assunto a ser assimilado.

Como é possível constatar, são muitas as mídias que podem oferecer interação aos assuntos, no entanto, é bem provável que o simulador, dentre as novas tecnologias utilizadas na educação no ensino de Física, seja a ferramenta que mais proporcione um aprendizado de forma lúdica, pois permite uma grande interação e autonomia do aluno com o conteúdo a ser estudado.

Vive-se em um novo tempo que exige formas diferentes de pensar e educar, o amplo acesso ao uso das novas tecnologias educacionais requerem novas metodologias na prática educacional. As TIC, caracterizadas como midiáticas, dessa forma não são apenas suportes. Estas interferem nas atitudes dos usuários, no modo de pensar, na forma de se relacionarem socialmente e na forma de buscarem conhecimento, isso tudo leva a uma nova cultura, um novo modelo de sociedade e principalmente de educação, pois não dá para continuar utilizando apenas uma ou duas metodologias de ensino, a informação não se encontra apenas escrita nos quadros e nos livros, estes, portanto não são os únicos locais em que o aluno deve buscar conhecimento [8].

Na perspectiva de Behrens (2000, p. 75, grifo do autor) [4] deve-se compreender que:

\begin{abstract}
Para romper com o conservadorismo, o professor deve levar em consideração que, além da linguagem oral e da linguagem escrita que acompanham historicamente o processo pedagógico de ensinar a aprender, é necessário considerar também a linguagem digital. Neste processo de incorporação ele precisa propor novas formas de aprender e de saber se apropriar criticamente de novas tecnologias, buscando recursos e meios para facilitar a aprendizagem.
\end{abstract}

Com o uso da linguagem digital, o professor encontra-se em um cenário inovador dispondo de incontáveis recursos para tornar a aula motivadora.

\title{
2.2. A FÍSICA NO ENSINO MÉDIO
}

A Física é vista por muitos alunos como uma matéria tediosa e difícil, por lidar com muitos conceitos abstratos, e ter a Matemática como uma ferramenta essencial no desenvolvimento de muitos assuntos.

Na Física, o aluno lida com fenômenos e matérias que na maioria das vezes, estão fora do alcance dos seus sentidos, como por exemplo, campo elétrico, campo magnético, partículas subatômicas, corpos com altas velocidades e processos dotados de grande complexidade [9].

Conforme os Parâmetros Curriculares Nacionais (PCN) no ensino de Física, o ideal seria partir da prática e de exemplos concretos para que a abstração estivesse sendo desenvolvida de forma gradual, no entanto, o que se observa é um privilégio dado à teoria e a abstração, desde as primeiras abordagens de cada assunto.

Enfatiza-se o uso de fórmulas e leis, em situações artificiais e desarticuladas, desvinculando a linguagem matemática de seu significado físico efetivo. Insiste-se na aplicação de exercícios repetitivos, com a finalidade de que a aprendizagem ocorra através da memorização e não por meio da construção do conhecimento, mediante as competências adquiridas [10].

Em síntese as aulas de Física tem se resumido principalmente na expressão do conhecimento aprendido por meio da linguagem matemática, no qual o desafio central para o educando consiste em identificar qual fórmula utilizar na resolução de inúmeros problemas. Não quer 
dizer que seja preciso abrir mão das fórmulas, até porque a formulação matemática sempre será relevante desde que desenvolvida com base nos conceitos e relações compreendidos anteriormente de forma qualitativa. O que se almeja, portanto, é a busca de novas e diferentes formas de expressão do saber da Física, ou seja, uma metodologia moderna, tanto do ponto de vista pedagógico quanto tecnológico [11].

Papert (apud Fiolhais e Trindade, 2003, p. 264) [2], faz ainda o seguinte alerta:

"[...] se aos estudantes só forem fornecidas equações como modelo da realidade, eles serão colocados numa posição onde nada nas suas ideias comuns é parecido ou reconhecido como física. Esta é uma situação que obviamente dificulta a aprendizagem."

Portanto, levando em consideração as competências e habilidades a serem desenvolvidos na Física no ensino médio, os PCN orientam que as aulas devam colaborar para que o aluno dentre outras:

- Desenvolva uma cultura científica efetiva, usando os conhecimentos da Física na interpretação dos fatos, fenômenos e processos naturais;

- Reconheça o sentido histórico da ciência e da tecnologia, compreendendo o desenvolvimento dos modelos físicos do passado para dimensionar corretamente os modelos atuais relacionando a evolução científica com a transformação da sociedade;

- Articule o conhecimento físico com conhecimentos de outras áreas do saber científico;

- Reconheça o papel da Física no sistema produtivo, compreendendo o desenvolvimento das tecnologias e sua relação dinâmica com a evolução do conhecimento científico;

- Compreenda dentre vários conteúdos, os fenômenos magnéticos para que saiba explicar, por exemplo, o campo magnético produzido por um ímã, ou por cargas elétricas em movimento assim como compreender fenômenos da natureza como magnetismo terrestre.

Como base nas competências supracitadas, se torna incontestável a necessidade de aulas lúdicas, que garantam uma participação mais ativa do aluno e que ofereça uma aprendizagem mais interativa e menos abstrata.

Para Fiolhais e Trindade (2003) [2], é do professor a responsabilidade de promover aos seus alunos experiências de aprendizagem mais eficazes, combater as dificuldades mais comuns e manter atualizados os instrumentos pedagógicos que utilizam.

\subsection{SIMULADORES}

Para Chaves (1988) [12], "Uma simulação é um modelo que pretende imitar um sistema, real ou imaginário, com base em uma teoria de operação desse sistema." Portanto, simulações são modelos computacionais que operam em representações matemáticas via linguagens de programação e que tem como finalidade fornecer animações que imitam situações e fenômenos reais ou imaginários [9].

Por permitir uma aprendizagem de forma interativa, essa ferramenta pedagógica possui considerável interesse para a educação, pois simulações tecnicamente e pedagogicamente bem elaboradas podem ser realizadas com bastante realismo, levando o aluno a uma construção menos abstrata de alguns conceitos e fenômenos físicos.

As simulações podem ser divididas em duas categorias, as estáticas e as interativas. A primeira permite pouca interatividade, pois o aprendiz não tem quase nenhum controle sobre os parâmetros [13]. Nas simulações interativas, a interação é possibilitada, pois é permitido manipular parâmetros e observar resultados imediatos, ocasionados pela modificação de situações e condições [14]. 


\subsection{VANTAGENS PEDAGÓGICAS DO SIMULADOR}

Em se tratando das vantagens que o simulador proporciona ao ensino de Física, o que interessa em primeiro lugar é o seu beneficio cognitivo. Ao manipular variáveis e parâmetros em uma simulação, o aluno poderá ter uma melhor compreensão sobre as relações de causa e efeito presentes no modelo estudado, experiência esta que não se assemelha ao conhecimento teórico, ou aula prática, nem mesmo ao acúmulo de uma tradição oral.

Através da simulação o aprendiz tem ainda a vantagem de explorar modelos mais complexos e em maior número do que se usasse apenas a construção mental. Dessa forma esta ferramenta tem a habilidade de ampliar a capacidade de imaginação e intuição do aluno [7].

Segundo os autores Fiolhais e Trindade (2003) [2]:

Embora as simulações não devam substituir por completo a realidade que representam, elas são bastante úteis para abordar experiências difíceis ou impossíveis de realizar na prática (por serem muito caras, muito perigosas, demasiado lentas, demasiado rápidas, etc.). Quando se revestem de um caráter de "jogo", as simulações fornecem uma recompensa pela realização de um certo objetivo.

Outro fator importante que merece destaque no uso da simulação é o fato desta proporcionar uma aprendizagem dialógica [5], pois o aluno ao manipular parâmetros de entrada e analisar as consequências de cada interação, começa a refletir e com isso passa a perguntar, questionar e criar hipóteses.

Essas novas atitudes resultam desse modo no aparecimento e percepção, pelo aprendiz, de relações e similaridades, entre as ideias apresentadas, que não foram previamente reconhecidas, levando-o assim a aprender através das suas próprias descobertas, que para Bruner (apud Cavalcanti e Holanda, 2010) [15] é essencialmente comparável à descoberta que um cientista faz em seu laboratório.

Em resumo, diante dos benefícios já explanados do uso de simulações virtuais no ensino de Física, tais mídias, conforme Medeiros e Medeiros (2002) [9] possuem ainda a capacidade de:

- Permitir aos alunos elaborar e testar hipóteses;

- Engajar os discentes em atividades com alto nível de interação;

- Envolver os educando em atividades que explicitem a natureza da pesquisa científica;

- Fazer com que conceitos abstratos se tornem mais concretos;

- Ajudar a identificar relacionamentos de causas e efeitos em sistemas complexos;

- Servir como um treinamento inicial para ajudar na compreensão do papel de um laboratório;

- Promover o raciocínio crítico;

- Fomentar uma compreensão mais efetiva dos fenômenos físicos;

- Acentuar os conceitos formados assim como promover a mudança conceitual.

Kenski (2004) [8], no entanto, alerta que, para o docente alcançar os objetivos pretendidos com a utilização deste recurso, o mesmo deverá saber utilizá-lo adequadamente procurando explorar o máximo suas especificidades.

Chaves (1988) [12] lembra ainda que depois do trabalho com simuladores, o professor precisa dar explicações aos alunos sobre os pressupostos utilizados na elaboração do modelo, de maneira a levar os discentes a compreenderem o porquê do modelo se comportar dessa, ou daquela forma e que também tenham em mente as limitações envolvidas no processo.

\subsection{CUIDADOS COM O USO INCORRETO DOS SIMULADORES}

Mesmo diante das inúmeras vantagens pedagógicas do uso de simuladores, é necessário que o professor tenha alguns cuidados no uso destes objetos educacionais, evitando possíveis prejuízos ao ensino. Como abordado anteriormente, as simulações nunca representam uma cópia fiel do real, dessa forma, o educador precisa ter a preocupação de deixar claro para os alunos que eles devem fazer suas deduções com base não sobre a simulação, mas sobre a realidade. 
Se tal situação não ficar explícita, corre-se o risco dos estudantes idealizarem que um dado fenômeno real ocorra exatamente como verificado no simulador, o que é um erro grave, pois as simulações não apresentam toda a complexidade de um fenômeno físico, por exemplo. Tais recursos na verdade possuem simplificações e aproximações o que causam a existência de algumas simulações com erros grosseiros ou exageros nas animações, podendo assim repassar imagens distorcidas e levar a interpretações equivocadas dos conceitos estudados [9].

Outro ponto a se destacar, segundo Chaves (1988) [12], é que não se podem substituir completamente as aulas em laboratório por simulações virtuais, visto que, ambas se completam. $\mathrm{O}$ aprendiz, por exemplo, nunca aprenderá a produzir uma fogueira somente através de uma simulação. Também é importante ter atenção na escolha dos simuladores, o professor deste modo deve se possível optar por softwares gratuitos, observar sua qualidade técnica e acima de tudo sua qualidade pedagógica.

\subsection{ELETROMAGNETISMO: O EXPERIMENTO DE OERSTED}

Considerando as dificuldades no aprendizado de Física, destacadas neste trabalho, principalmente com relação aos conteúdos de eletromagnetismo, é explorado na seção 3 , as etapas de uma simulação virtual com uso do smartphone.

Devido a sua grande importância, tanto a partir de uma perspectiva histórica como pelo fato de representar o ponto de unificação entre os grandes tópicos da Física eletricidade e magnetismo, optou-se por abordar a simulação virtual do "O experimento de Oersted".

Como para a compreensão do experimento é necessário que o aluno visualize mentalmente fenômenos abstratos como, campo magnético, linhas de indução e corrente elétrica, este assunto é um bom exemplo de como utilizar simuladores via smartphone, no ensino de Física a luz das teorias de aprendizagem, a fim de proporcionar um ensino mais lúdico, interativo, contextualizado e significativo para o aluno.

\section{RESULTADO E DISCUSSÕES}

Para trabalhar com o assunto, "O experimento de Oersted" foi escolhido o simulador "Oersted" (fig. 1), aplicativo que aborda de maneira dinâmica o funcionamento do experimento, conceitos, regras, atividades e um pouco da história da Física relacionada ao tema. O simulador é gratuito e foi produzido pelo Sistema Brasileiro de Ensino S. A. (SEB).

O download do simulador pode ser realizado em um aparelho smartphone com sistema operacional Android ou Windows Phone. Para isso o aparelho deve estar conectado a internet, sendo assim é importante que a escola disponibilize internet Wi-Fi.

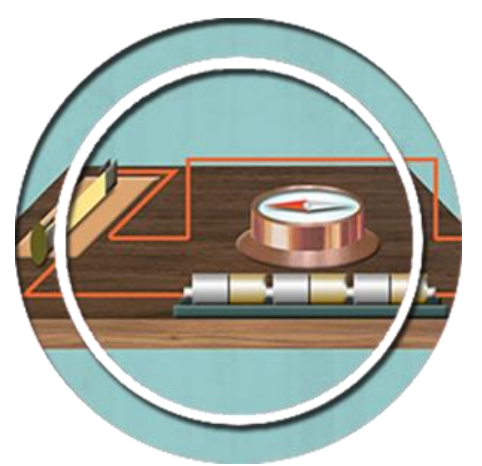

Figura 1-Aplicativo Oersted APK for Windows Phone

Um ponto negativo a ser considerado é a possibilidade de que alguns estudantes não possuam smartphone, no entanto a principal finalidade da proposta é saber fazer uso desta ferramenta em sala de aula de forma a trazer contribuições para o ensino, logo o professor para contornar a situação, poderá formar grupos, a fim de que cada um tenha pelo menos um 
aparelho. O importante é que todos aprendam a baixar os simuladores e que saibam utilizá-los, pois mesmo aqueles que não possuem o aparelho, podem utilizar o smartphone dos pais, dos irmãos ou mesmo de amigos, o que tem como consequência positiva a disseminação de conhecimento científico.

\subsection{APLICATIVO: SIMULADOR “OERSTED”}

Ao executar o aplicativo é apresentado um modelo do experimento realizado pelo físico Hans Cristian Oersted. O experimento é composto por uma bússola e um circuito elétrico básico, constituído por um fio condutor, uma fonte de energia (pilhas) e uma chave que permite acionar e desligar o circuito. De posse de uma bússola em equilíbrio, orientada pelo campo magnético terrestre, montasse o circuito elétrico de forma que a bússola fique posicionada sob um segmento retilíneo do fio e sua agulha imantada fique paralela ao fio quando o circuito encontra-se aberto, ou seja, sem passagem de corrente elétrica (fig. 2).

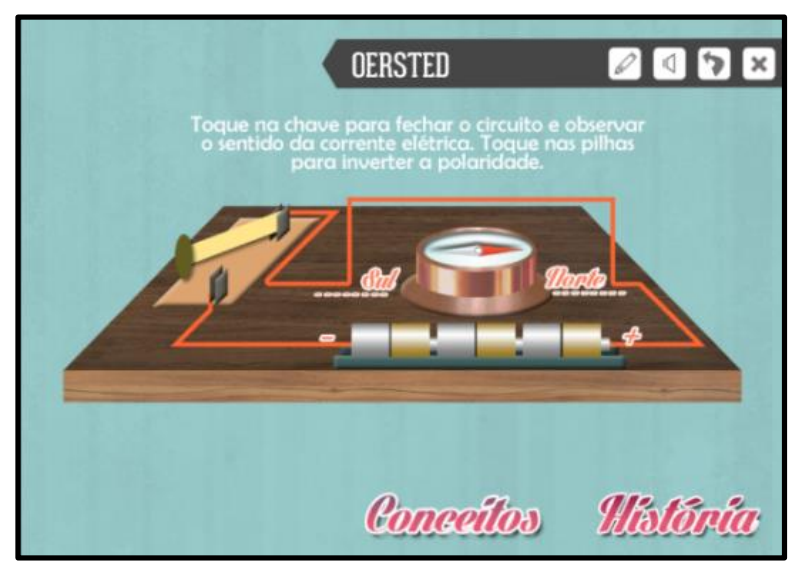

Figura 2 - Experimento de Oersted (circuito aberto)

Logo acima do experimento (fig. 2), aparece um tutorial que dá o comando para que o aprendiz realize algumas interações, como tocar na chave para fechar o circuito e tocar nas pilhas para inverter a polaridade. Ao fechar o circuito, a agulha da bússola muda de direção e se orienta perpendicular ao fio. Ao mudar a polaridade das pilhas uma seta indica a inversão do sentido da corrente elétrica, assim como também é possível observar uma inversão no sentido da agulha imantada (fig. 3). Nesse momento o professor poderá aproveitar para provocar nos alunos algumas reflexões, como: Por que quando o circuito é fechado à agulha da bussola se movimentou? Por que a agulha ficou perpendicular ao fio? Por que ao mudar o sentido da corrente o sentido da agulha também muda? O que aconteceria se a bússola fosse colocada sobre o fio? E se no inicio a agulha já estivesse posicionada perpendicular ao fio, será que ao ligar o circuito ela ficaria paralela?

$\mathrm{Na}$ fig. 3 é possível verificar a posição da agulha em dois momentos diferentes, onde cada posição está relacionada a um dos sentidos da corrente. É importante aqui, que o professor alerte aos alunos que o simulador é apenas uma forma de ilustração do fenômeno, pois num experimento real a agulha da bússola sofre a influência de dois campos magnéticos principais, o campo magnético gerado pelo circuito é outro pela Terra, logo a agulha irá se equilibrar, orientada pela resultante entre estes dois campos e não perpendicular ao fio, como apresentado no simulador.

Dessa forma, no modelo simulado deve-se considerar que o campo elétrico gerado pelo circuito é muito mais intenso do que o campo produzido pela Terra, de forma que este possa ser desprezado. 


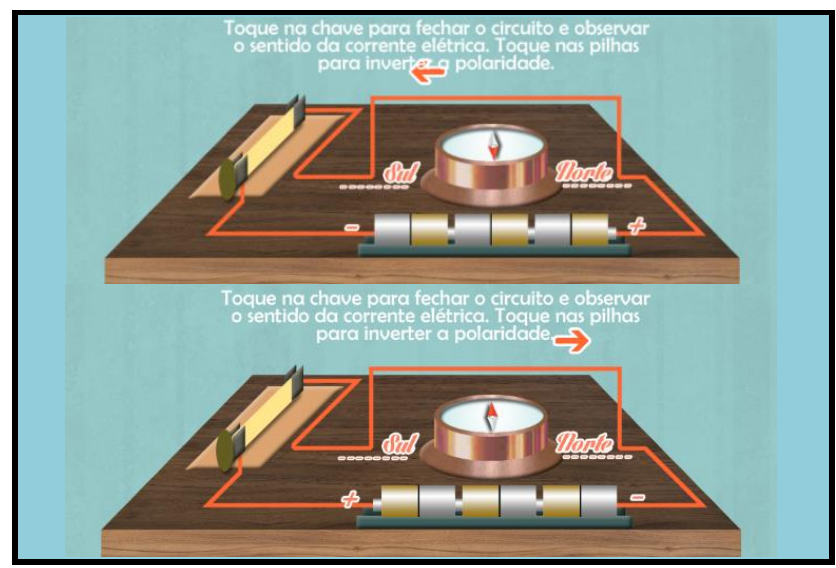

Figura 3 - Experimento de Oersted (circuito fechado)

Como a confecção do experimento é simples, aconselha-se que o educador procure realizar sua construção juntamente com os alunos como atividade, e assim fazer uma comparação entre $\mathrm{o}$ experimento real e o modelo simulado, para que fique mais perceptível à passagem de corrente elétrica pelo circuito, aconselha-se acrescentar uma pequena lâmpada.

$\mathrm{O}$ discente poderá aproveitar para mostrar ainda que qualquer aparelho elétrico em funcionamento pode interferir no sentido da agulha da bússola como, um celular. Mostrando assim a importância de ao manipular uma bússola ter o cuidado de não mantê-la muito próxima a campos magnéticos que possam provocar interferências consideráveis.

Antes de dar continuidade às próximas etapas do simulador o professor poderá aproveitar para relembrar alguns assuntos necessários para o entendimento do experimento, como: o conceito de corrente elétrica, sentido real e sentido convencional da corrente, conceito de campo magnético, linhas de indução, polaridades de um ímã e o campo magnético gerado por um fio condutor retilíneo.

Logo após, poderá utilizar o simulador para ensinar aos alunos a "regra da mão direita" (fig. 4), uma forma prática de determinar o sentido das linhas do campo elétrico geradas por uma corrente elétrica. No caso do experimento de Oersted, a regra ajudará o aluno a identificar o sentido, para onde o polo norte da agulha apontará, quando esta interagir com o circuito elétrico em funcionamento. Clicando no ícone conceitos o simulador apresenta um tutorial informativo sobre a regra, assim como uma animação que mostra como se deve imaginar a mão direita segurando o fio, onde o polegar aponta no sentido da corrente enquanto que os demais dedos automaticamente fornecem o sentido do campo em cada ponto na região do fio $\mathrm{e}$ consequentemente no caso do experimento de Oersted, indica o sentido do polo norte da agulha da bússola. Observando a fig. 4, verifica-se que as linhas de campo magnético são fechadas, concêntricas com o condutor e situadas em planos perpendiculares a ele [16].

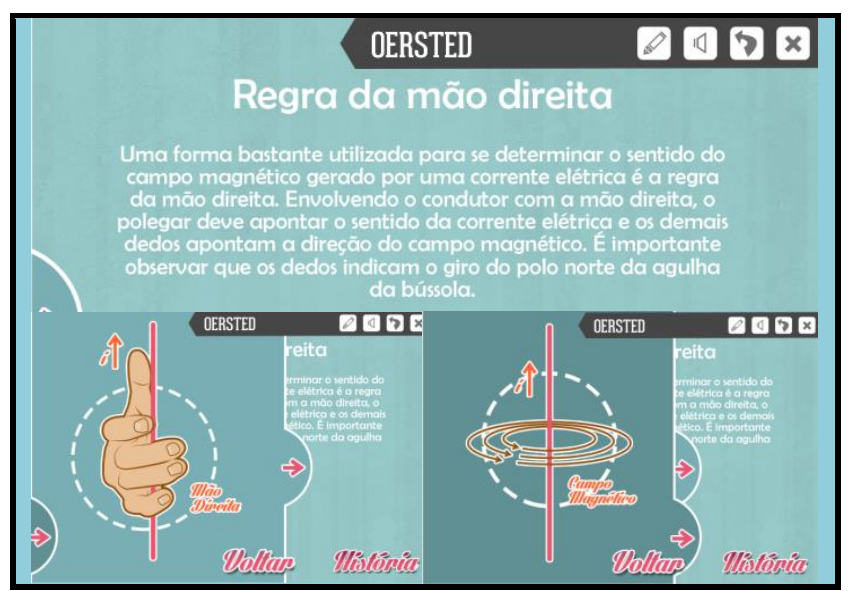

Figura 4 - Regra da mão direita 
Outra vantagem relevante deste simulador é a possibilidade de trabalhar um pouco da história da Física (fig 5). Ao clicar no ícone história do aplicativo é apresentado um breve resumo de quem foi Oersted e a importância do seu experimento para a construção do eletromagnetismo:

Até o início do século XIX não se sabia de nenhuma relação entre eletricidade e magnetismo, embora ambos os fenômenos já fossem estudados. O eletromagnetismo foi descoberto pelo físico dinamarquês Hans Cristian Osterd (Rudkobing, 14 de agosto de a 1777 - Copenhaga, 9 de março de 1851). Enquanto se preparava para uma palestra na tarde de 21 de abril de 1820, Orsted desenvolveu um experimento que o surpreendeu: enquanto preparava os seus materiais, reparou que a agulha de uma bússola se desviava do norte magnético quando a corrente elétrica da bateria era ligada e desligada. Isso o convenceu de que um fio carregando uma corrente elétrica gera um campo magnético, é que isso confirmava uma relação direta entre eletricidade e magnetismo.

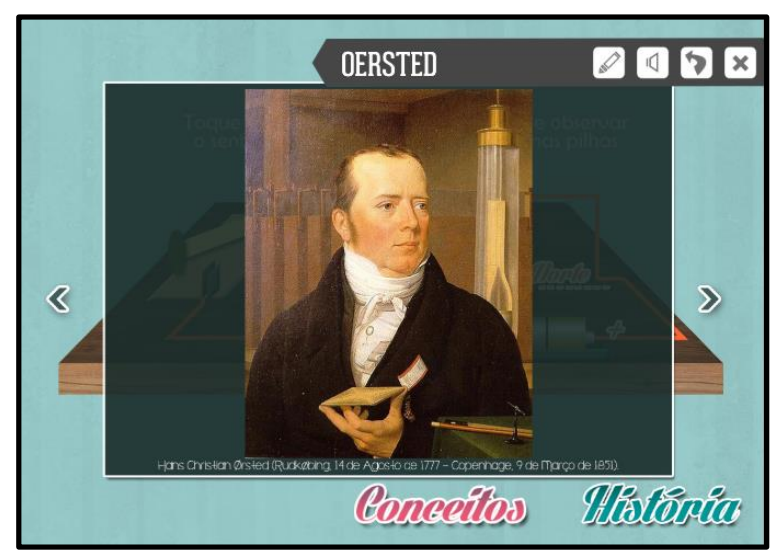

Figura 5-Oersted (1777 - 1851)

Para uma melhor fixação dos assuntos estudados no simulador, também encontra-se algumas atividades. Na atividade 1 (fig. 6), por exemplo, é apresentado um modelo do experimento de Oersted, onde o circuito encontra-se aberto e portanto sem passagem de corrente elétrica. $\mathrm{O}$ comando da atividade solicita ao aluno que este toque na imagem da bússola que melhor representa a orientação da agulha quando o circuito for ligado. Se por ventura o aluno escolher a bússola errada e tocar no ícone confirmar surgirá à frase, "tente novamente", se ele acertar, aparecerá à frase "correto!". Na atividade o educando poderá aplicar a regra da mão direita.

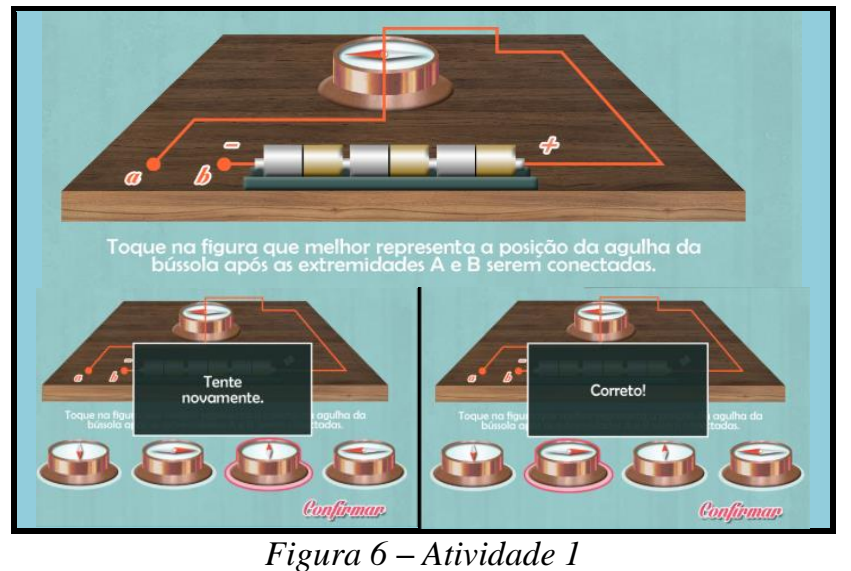

$\mathrm{Na}$ atividade 2 (fig.7) é dado um circuito fechado por onde passa uma corrente elétrica, o enunciado da atividade solicita ao aprendiz, que este arraste para a bússola a agulha que melhor representa a orientação do campo magnético no fio, naquele local. Para ter êxito nesta atividade o aluno deve lembrar que a agulha da bússola indica a existência de um campo magnético, sua direção e sentido, deve também reconhecer o sentido da corrente elétrica analisando a polaridade do conjunto de pilhas e aplicar corretamente a regra da mão direita. 


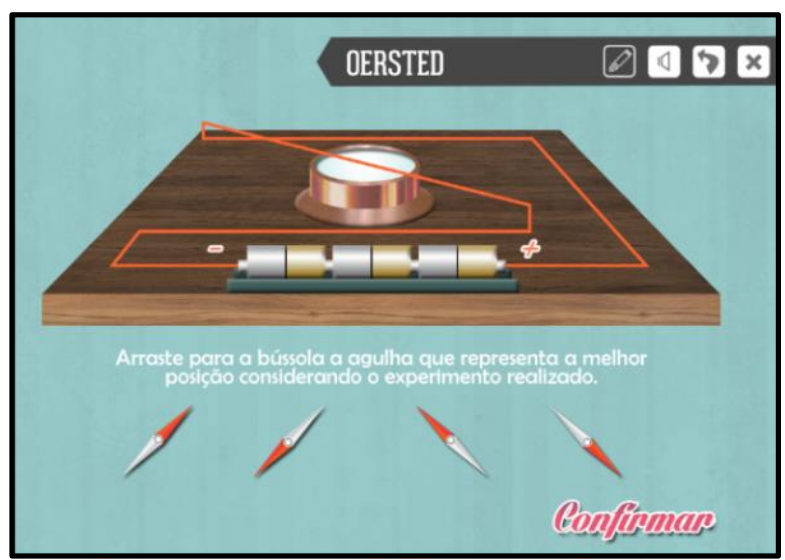

Figura $7-$ Atividade 2

$\mathrm{Na}$ atividade 3 (fig. 8) novamente é apresentado outro modelo do experimento de Oersted, no entanto agora a atividade informa que o circuito elétrico está em funcionamento é que a posição da agulha da bússola encontra-se orientada pelo campo magnético produzido pela corrente que percorre o fio. $\mathrm{O}$ comando da atividade, portanto solicita que o aprendiz arraste os elementos abaixo do experimento $(+,-, \leftarrow, \rightarrow)$, para as respectivas lacunas. Esta é atividade mais interativa do simulador, pois o aluno precisará dispor os elementos do experimento de forma que a situação dada seja verdadeira. Como a agulha da bússola se orienta pelo campo magnético do circuito, é possível ao aluno utilizando a regra da mão direita descobrir o sentido da corrente elétrica e assim, consequentemente a polaridade do conjunto de pilhas que estão em série.

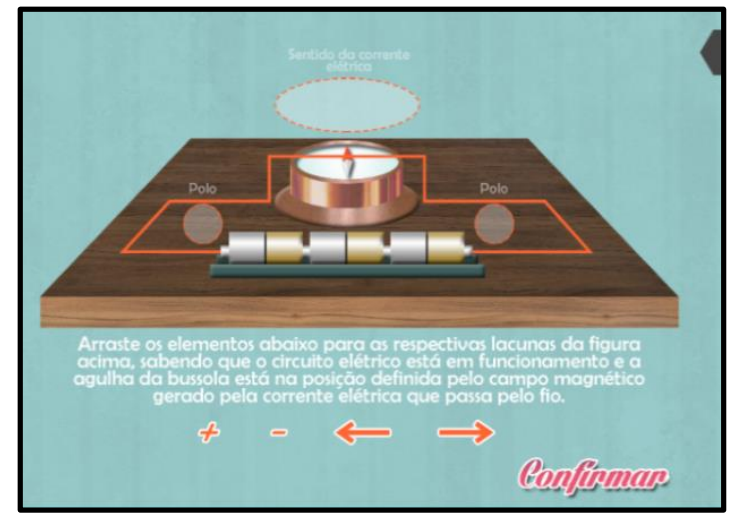

Figura 8-Atividade 3

Ao final com base nos acertos e erros, o simulador apresenta uma medalha com o total de rendimento do aluno, o que colabora para que as atividades sejam apresentadas de forma mais divertida aos estudantes, devido ao caráter de jogo e de competição (fig. 9).

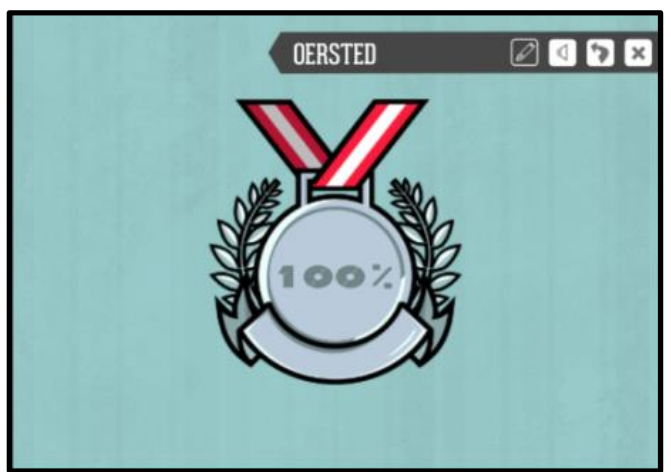

Figura 9-Rendimento total nos exercícios 
De posse dos conceitos e fenômenos estudados e exercitados e a fim de garantir uma aprendizagem mais significativa, o professor poderá promover uma discussão com os alunos sobre campo magnético terrestre, realizando assim uma ponte com outras áreas do conhecimento científico.

É importante, por exemplo, que o aluno saiba que o campo magnético da Terra está relacionado ao seu núcleo metálico líquido (níquel e ferro) e as correntes elétricas presentes nele, portanto a Terra funciona como um imenso ímã. Definiu-se um eixo magnético para o planeta que passa pelos seus polos magnéticos, algo semelhante ao eixo de rotação que corta os polos geográficos do planeta, no entanto o polo sul magnético terrestre fica próximo do polo norte geográfico para onde aponta o polo norte da bússola. É importante também mencionar que o campo magnético da Terra sofre variações ao longo de determinados períodos e também variações mais rápidas locais por causa de diversos fatores como as correntes elétricas existentes na ionosfera, a atividade magnética do Sol e as propriedades magnéticas de diversas rochas [17].

- Como forma de realizar uma maior contextualização dos assuntos trabalhados o educador poderá solicitar a pesquisa de alguns temas sobre, por exemplo:

- As cartas magnéticas que são utilizadas em diferentes áreas do conhecimento como na orientação em topografia, navegação marítima e aérea; aplicações bélicas e na localização de jazidas de minérios;

- Espécies de animais que utilizam o campo magnético terrestre para se orientarem;

- A proteção que o campo magnético terrestre fornece aos seres vivos contra a radiação cósmica provocada pelo bombardeio de partículas carregadas lançadas pelo vento solar.

\section{CONSIDERAÇÕES FINAIS}

Este artigo voltou-se para a proposta de metodologias focadas no uso de simuladores via smartphone, com a finalidade de promover um ensino menos abstrato de conteúdos de Física, como os conceitos de eletromagnetismo. Sendo assim, procurou-se apresentar algumas estratégias que almejam garantir ao aluno um papel mais ativo no processo de ensino e aprendizagem. Evoluindo deste modo, de uma educação tradicional, baseada apenas na transmissão de conhecimento para um modelo construtivista que estimule no aluno a reflexão e o pensamento crítico.

O smartphone como estratégia didática foi o recurso escolhido por ser uma TIC portátil bastante difundido entre os jovens do ensino médio e por ser também utilizado quase sempre de forma imprópria durante as aulas, o que tem causado transtornos para muitos professores. Sendo assim, mediante os exemplos aqui trabalhados demonstrou-se, que existem maneiras de se utilizar esta ferramenta de enorme potencial didático no ensino de Física de forma a apresentar de modo menos abstrato alguns conceitos, assim como promover uma aprendizagem mais interativa.

São muitas as possibilidades de uso do smartphone no ensino. É possível trabalhar com imagens, produção de vídeos, realizar discussões através de redes sociais, pesquisa pela internet, no entanto, dentre os vários recursos disponíveis, escolheu-se o simulador devido à interatividade que este consegue promover entre aluno e conteúdo. Estes programas possuem a vantagem de descrever fenômenos que seriam muito difíceis de serem realizados na prática, até mesmo em laboratório. Além disso, tem a característica de acionar vários canais sensoriais durante o aprendizado.

Através da simulação do experimento de Oersted, verifica-se que é possível trabalhar de forma mais lúdica e interativa, conceitos abstratos do eletromagnetismo como, campo magnético, linhas de campo e corrente elétrica, o que possibilita aos aprendizes gerarem e testarem hipóteses, propiciando uma melhor compreensão dos modelos físicos e maior envolvimento destes durante as aulas. Foi possível ainda mostrar o mecanismo de funcionamento da bússola, além de realizar uma abordagem histórica do experimento de Oersted, que apesar de simples foi um dos mais importantes da Física por unir os fenômenos elétricos aos magnéticos. 
Além das metodologias relacionadas ao uso de simuladores via smartphones aqui abordadas, o educador também poderá estar utilizando outros recursos midiáticos e estratégias de ensino através do aparelho, como:

- Pedir para os alunos formarem grupos e utilizar o smartphone na confecção de vídeos, onde estes devem mostrar a construção de determinados experimentos e explicar seu funcionamento assim como os conceitos físicos abordados;

- Criar grupos no WhatsApp ou Facebook voltados para o compartilhamento de imagens, vídeos, e opiniões voltados para o conteúdo trabalhado;

- Incentivar os alunos no uso de aplicativos como calculadoras científicas, tabelas de constantes físicas e conversores de unidade dentre outros aplicativos voltados para o ensino de Física.

Apesar da sua eficiência como foi abordado nesse trabalho quanto aos conceitos sobre Eletromagnetismo, ressalta-se, que as simulações via smartphone devem ser usadas como um recurso complementar no processo de ensino-aprendizagem, estas não devem substituir as aulas em laboratório, mais sim servirem como um recurso a mais no ensino.

\section{REFERÊNCIAS BIBLIOGRÁFICAS}

1. Smolka ALB, Magiolino LLS. História da Pedagogia: Modos de ensinar, sentir e pensar. Revista Educação. 2010 ago; 2: 30 - 39.

2. Fiolhais C, Trindade J. Física no Computador: o Computador como uma Ferramenta no Ensino e na Aprendizagem das Ciências Físicas. Revista Brasileira de Ensino de Física. [internet]. 2003. $\begin{array}{llllll}\text { [acesso } 2015 & \text { jan } 10] ; & 25(3): & 259-272 . & \text { Disponível em }\end{array}$ http://www.sbfisica.org.br/rbef/pdf/v25_259.pdf.

3. Pires MA, Veit EA. Tecnologias de Informação e Comunicação para ampliar e motivar o aprendizado de Física no Ensino Médio. Revista Brasileira de Ensino de Física. [internet]. 2006. [acesso 2015 jan 10]; 28(2): 241-248. Disponível em http://sbfisica.org.br/rbef/pdf/050903.pdf.

4. Behrens, M A. Projetos de Aprendizagem Colaborativa num Paradigma Emergente. ln: Moran JM, Masetto MT, Behrens MA. Novas Tecnologias e mediação pedagógica. 3. ed. Campinas (SP): Papirus; 2000. p. 67-129

5. Freire P. Pedagogia Do Oprimido. 17. ed. Rio de Janeiro: Paz e Terra; 2005.

6. Moreira MA. Teorias de Aprendizagem. 2. ed. São Paulo: EPU; 2011.

7. Lévy P. As tecnologias da inteligência: o futuro do pensamento na era da informática. Rio de Janeiro: 34 Ltda; 1993.

8. Kenski VM. Tecnologias e ensino presencial e a distância. 2. ed. Campinas: Papirus; 2004.

9. Medeiros A, Medeiros CF. Possibilidades e limitações das simulações computacionais no ensino da física. Revista Brasileira de Ensino de Física. [internet]. 2002. [acesso 2015 jan 10];24(2):7786. Disponível em http://www.sbfisica.org.br/rbef/pdf/v24_77.pdf.

10. Brasil. Ministério da Educação, Secretaria de Educação Média e Tecnológica. Parâmetros Curriculares Nacionais do Ensino Médio - PCN. [internet]. Brasília; 1999. [acesso 2015 jan 20]. Disponível em http://portal.mec.gov.br/seb/arquivos/pdf/ciencian.pdf.

11. Brasil. Ministério da Educação, Secretaria de Educação Média e Tecnológica. PCN+ Ensino Médio: Orientações Educacionais Complementares aos Parâmetros Curriculares Nacionais. [internet]. Brasília: 2002. [acesso 2015 jan 20]. Disponível emhttp://portal.mec.gov.br/seb/arquivos/pdf/CienciasNatureza.pdf .

12. Chaves EOC. O Uso de Computadores em Escolas: Fundamentos e Críticas [internet]. São Paulo: Scipione; 1988. [acesso 2015 jan 10] Disponível em http://www.ich.pucminas.br/pged/db/wq/wq1/local/ec_scipione.htm.

13. Coelho RO. O Uso da Informática no Ensino de Física de Nível Médio. [Dissertação] [internet]. Pelotas: Universidade Federal de Pelotas; 2002. [acesso 2015 jan 10]. Disponível em http://www2.pelotas.ifsul.edu.br/coelho/inf_ens_fis_med.pdf.

14. Heckler V, Saraiva MFO; Oliveira Filho KS. Uso de simuladores, imagens e animações como ferramentas auxiliares no ensino/aprendizagem de óptica. Revista Brasileira de Ensino de Física. 2007. [internet]. [acesso 2015 jan 10]; 29(2): 267-273. Disponível em http://www.scielo.br/pdf/rbef/v29n2/a11v29n2.

15. Cavalcant FO, Holanda CJ. Teorias da Aprendizagem: texto introdutório.[internet][S.1.]: UFRGS; 2010. 40 p. [acesso 2015 jan 15]. Disponível em: 
http://www.ufrgs.br/uab/informacoes/publicacoes/materiais-de-fisica-para-educacaobasica/teorias_de_aprendizagem_fisica.pdf.

16. Oliveira MPP, Pogibin A, Oliveira RCA, Romero TRL. Física Conceitos e Contextos: pessoal, social, histórico, eletricidade e magnetismo, ondas eletromagnéticas, radiação e matéria. São Paulo: FTB; 2013.

17. Barreto Filho B, Silva CX. Física aula por aula: eletromagnetismo, ondulatória, física moderna. São Paulo: FTB; 2013. 